OPEN ACCESS

Edited by:

Jean Rivoal,

Université de Montréal, Canada

Reviewed by:

Abir U. Igamberdiev,

Memorial University of Newfoundland,

Canada

Subhash C. Minocha

University of New Hampshire,

United States

*Correspondence:

Barry J. Shelp

bshelp@uoguelph.ca

${ }^{\dagger}$ Present address:

Jeffrey P. Simpson,

Department of Biochemistry, Purdue

University, West Lafayette,

IN, United States

FThese authors have contributed equally to this work.

Specialty section:

This article was submitted to

Plant Physiology,

a section of the journal

Frontiers in Plant Science

Received: 03 April 2017

Accepted: 27 July 2017

Published: 14 August 2017

Citation:

Zarei A, Brikis CJ, Bajwa VS,

Chiu GZ, Simpson JP, DeEll JR,

Bozzo GG and Shelp BJ (2017) Plant

Glyoxylate/Succinic Semialdehyde

Reductases: Comparative

Biochemical Properties, Function during Chilling Stress, and Subcellular Localization. Front. Plant Sci. 8:1399.

doi: 10.3389/fpls.2017.01399

\section{Plant Glyoxylate/Succinic Semialdehyde Reductases: Comparative Biochemical Properties, Function during Chilling Stress, and Subcellular Localization}

\author{
Adel Zarei" ${ }^{1 \neq}$ Carolyne J. Brikis ${ }^{1 \neq}$, Vikramjit S. Bajwa ${ }^{1}$, Greta Z. Chiu', \\ Jeffrey P. Simpson ${ }^{1 \dagger}$, Jennifer R. DeEll ${ }^{2}$, Gale G. Bozzo ${ }^{1}$ and Barry J. Shelp ${ }^{1 *}$ \\ ${ }^{1}$ Department of Plant Agriculture, University of Guelph, Guelph, ON, Canada, ${ }^{2}$ Ontario Ministry of Agriculture, Food and \\ Rural Affairs, Simcoe, ON, Canada
}

Plant NADPH-dependent glyoxylate/succinic semialdehyde reductases 1 and 2 (cytosolic GLYR1 and plastidial/mitochondrial GLYR2) are considered to be of particular importance under abiotic stress conditions. Here, the apple (Malus $\times$ domestica Borkh.) and rice (Oryza sativa L.) GLYR1s and GLYR2s were characterized and their kinetic properties were compared to those of previously characterized GLYRs from Arabidopsis thaliana [L.] Heynh. The purified recombinant GLYRs had an affinity for glyoxylate and succinic semialdehyde, respectively, in the low micromolar and millimolar ranges, and were inhibited by NADP ${ }^{+}$. Comparison of the GLYR activity in cell-free extracts from wild-type Arabidopsis and a glyr1 knockout mutant revealed that approximately 85 and $15 \%$ of the cellular GLYR activity is cytosolic and plastidial/mitochondrial, respectively. Recovery of GLYR activity in purified mitochondria from the Arabidopsis glyr1 mutant, free from cytosolic GLYR1 or plastidial GLYR2 contamination, provided additional support for the targeting of GLYR2 to mitochondria, as well as plastids. The growth of plantlets or roots of various Arabidopsis lines with altered GLYR activity responded differentially to succinic semialdehyde or glyoxylate under chilling conditions. Taken together, these findings highlight the potential regulation of highly conserved plant GLYRs by NADPH/NADP+ ratios in planta, and their roles in the reduction of toxic aldehydes in plants subjected to chilling stress.

Keywords: abiotic stress, aldehyde detoxification, mutants, overexpression, redox homeostasis, substrate promiscuity

\section{INTRODUCTION}

Under stress conditions such as chilling, drought and salinity, toxic aldehydes can accumulate in plants and interact with DNA, lipids and proteins, or influence the transcription of stress-related genes, thereby causing cellular and developmental problems (Weber et al., 2004; Kotchoni et al., 2006; Yamauchi et al., 2011; Mano, 2012; Biswas and Mano, 2015; Srivastava et al., 2017; see references therein). Altering activities of enzymes that modify the aldehyde chemical grouping has been shown to affect plant tolerance to various stresses (Oberschall et al., 2000; Bouché et al., 2003; 
Sunkar et al., 2003; Zarei et al., 2016), indicating that detoxification of aldehydes is important for maintaining plant health.

Succinic semialdehyde (SSA) is a mitochondrially generated intermediate in the metabolism of 4-aminobutyrate (GABA), which accumulates in response to abiotic stresses (Bown and Shelp, 1997; Shelp et al., 1999; Kinnersley and Turano, 2000). SSA is typically oxidized to succinate via SSA dehydrogenase (Tuin and Shelp, 1994; Bouché et al., 2003), but evidence is available for the generation of 4-hydroxybutyrate (GHB) from SSA in response to hypoxia, high light, salinity, drought and chilling (Allan et al., 2003, 2008, 2012; Breitkreuz et al., 2003; Fait et al., 2005). Glyoxylate can be generated in various subcellular compartments and biochemical processes: the peroxisome during the photorespiratory or non-photorespiratory synthesis of serine (Bauwe et al., 2010; Hoover et al., 2013; Ros et al., 2014); the glyoxysome during fatty acid catabolism (Kunze et al., 2006); the cytosol during the interconversion of organic acids (Eprintsev et al., 2015); and the endoplasmic reticulum during purine catabolism (Werner and Witte, 2011). Glycolate, the precursor of glyoxylate in photorespiration, is known to accumulate under hypoxic conditions, and both glycolate and glyoxylate accumulate with the suppression of glycolate oxidase (Narsai et al., 2009; Lu et al., 2014).

Several mechanisms can be involved in the detoxification of glyoxylate: transamination to glycine (e.g., GABA transaminase); decarboxylation to formate; oxidation to oxalate; and, reduction to glycolate (Givan and Kleczkowski, 1992; Bauwe et al., 2010; Peterhansel et al., 2010; Shelp et al., 2012a; Igamberdiev and Eprintsev, 2016; see references therein). Our laboratory has biochemically characterized two NADPH-dependent glyoxylate reductases (EC 1.1.1.79) from Arabidopsis thaliana (L.) Heynh. (GLYR1, GenBank accession no. AAK94781; GLYR2, (GenBank accession no. AAP42747) that efficiently convert glyoxylate into glycolate (Hoover et al., 2007a,b; Simpson et al., 2008). Notably, they also convert SSA into GHB, albeit with lower catalytic efficiency than for the glyoxylate to glycolate conversion (2-12 vs. $660-2870 \mathrm{~s}^{-1} \mathrm{mM}^{-1}$, see Table $\mathbf{1}$ for additional information), and constitutive expression of AtGLYR1 in an SSA dehydrogenase-deficient yeast enables growth on $20 \mu \mathrm{M}$ GABA and significantly enhances cellular GHB levels (Breitkreuz et al., 2003). Furthermore, glyr1 and glyr2 single mutants of Arabidopsis accumulate less GHB with submergence stress than the wild-type (WT) (Allan et al., 2012). A gaba transaminase/ssa dehydrogenase double mutant of Arabidopsis accumulates both SSA and GHB, and is more sensitive to exogenous SSA or GHB than WT plants (Ludewig et al., 2008). Both WT and glyr1/2 double mutants of Arabidopsis are more sensitive to exogenous SSA than GHB under ambient conditions, suggesting that GHB accumulation in ssa dehydrogenase mutants and during abiotic stress is a response for avoiding SSA toxicity (Mekonnen and Ludewig, 2016). Further research is required to establish whether a differential phenotype is associated with the glyrl/glyr2 double mutants under abiotic stress conditions.

Arabidopsis GLYR1 and GLYR2 activities have strong affinity for NADPH $\left(K_{\mathrm{m}}=1.2-2.6 \mu \mathrm{M}\right.$; see Table 1 for additional information), regardless of whether glyoxylate or SSA is the substrate, and AtGLYR1 is known to be competitively inhibited by $\mathrm{NADP}^{+}$(Hoover et al., 2007a,b; Simpson et al., 2008). The ratio of $\mathrm{NADPH} / \mathrm{NADP}^{+}$in mature leaves of Arabidopsis and tobacco increases from approximately 2 to $3-5$ with submergence and heat stresses, and to 8 with chilling (Allan et al., 2008). In the absence of applied stress, the NADPH/NADP ${ }^{+}$ratio in an NAD KINASE1 overexpression line of Arabidopsis is increased by threefold, and there is a corresponding increase in GHB accumulation (Allan et al., 2012).

Arabidopsis GLYR1 and GLYR2 are moderately expressed throughout the plant, including roots and imbibed seed, but GLYR2 expression is more highly associated than GLYR1 with rosette leaves, which are known to highly express photorespiratory genes (Foyer et al., 2009; Shelp et al., 2012b). With the exception of two studies (Allan et al., 2008, 2012), there is little evidence for the stress-induced expression of GLYRs (Shelp et al., 2012b; Zarei et al., 2017; see references therein). Furthermore, transient GHB accumulation in cold-acclimated Arabidopsis plants (Kaplan et al., 2007) and rice seed germinated under hypoxia (Narsai et al., 2009) seems to be independent of GLYR expression (see Shelp et al., 2012b). Overall, these in vitro and in planta studies support the operation and redox regulation of glyoxylate- and SSA-dependent GLYR activities under abiotic stress conditions, as suggested previously (Allan et al., 2008, 2012).

Early research indicated that NADPH-dependent GLYR activity is located in both cytosol and plastids (Givan et al., 1988; also see review by Givan and Kleczkowski, 1992). Recently, Simpson et al. (2008), Ching et al. (2012), Brikis et al. (2017) established, using various transient and stable expression systems, in combination with appropriate organelle markers, that GLYR1s from apple (Malus $\times$ domestica Borkh.) and rice (Oryza sativa L.), as well as Arabidopsis, are exclusively cytosolic, whereas the GLYR2s are localized to both mitochondria and plastids. Apple and rice GLYRs have not yet been biochemically characterized.

In the present study, we demonstrated that: (i) GLYRs from apple and rice, like those from Arabidopsis, display higher affinity and catalytic efficiency for glyoxylate than for SSA; (ii) the activity of apple GLYRs is inhibited by $\mathrm{NADP}^{+}$; (iii) the growth of plantlets or roots of various Arabidopsis lines with altered GLYR activity respond differentially to exogenous SSA, GHB or glyoxylate under chilling conditions; and (iv) approximately 85 and $15 \%$ of the total GLYR activity in Arabidopsis is present in the cytosol and plastids/mitochondria, respectively. Taken together, these findings highlight the potential roles of GLYRs in the reduction of toxic aldehydes within distinct compartments of the plant cell during exposure to chilling conditions.

\section{MATERIALS AND METHODS}

\section{Plant Material, and Gene Expression and Southern Analysis}

Arabidopsis thaliana (L.) Heynh. ecotype Columbia (Col-0) was the genetic background for the WT and all transgenic/mutant lines. Seeds were sterilized in a closed container using a 
TABLE 1 | Comparison of the kinetic parameters for purified recombinant GLYRs from apple, rice, and Arabidopsis.

\begin{tabular}{|c|c|c|c|c|c|}
\hline $\begin{array}{l}\text { Varied } \\
\text { substrate }\end{array}$ & $\begin{array}{l}\text { Fixed } \\
\text { substrate }\end{array}$ & $\begin{array}{l}K_{\mathrm{m}} \\
\mu \mathrm{M}\end{array}$ & $\begin{array}{c}V_{\max } \\
\mu \mathrm{mol} \mathrm{min}^{-1} \\
\mathrm{mg}^{-1} \text { protein }\end{array}$ & $\begin{array}{l}k_{\text {cat }} \\
s^{-1}\end{array}$ & $\begin{array}{c}k_{\text {cat }} / K_{\mathrm{m}} \\
\mathrm{s}^{-1} \mathrm{mM}^{-1}\end{array}$ \\
\hline \multicolumn{6}{|l|}{ MdGLYR1 } \\
\hline Glyoxylate & NADPH & $14.1 \pm 2.1$ & $54.7 \pm 6.7$ & $30.9 \pm 3.8$ & $2230 \pm 153$ \\
\hline NADPH & Glyoxylate & $3.3 \pm 0.5$ & $39.4 \pm 6.1$ & $22.3 \pm 3.4$ & $6803 \pm 278$ \\
\hline SSA & NADPH & $1133 \pm 273$ & $8.1 \pm 2.9$ & $4.6 \pm 1.6$ & $5.1 \pm 2.3$ \\
\hline NADPH & SSA & $7.4 \pm 1.9$ & $9.8 \pm 1.0$ & $5.5 \pm 0.6$ & $832 \pm 166$ \\
\hline \multicolumn{6}{|l|}{ MdGLYR2 } \\
\hline Glyoxylate & NADPH & $23.9 \pm 1.9$ & $34.3 \pm 3.7$ & $19.1 \pm 2.1$ & $796 \pm 33$ \\
\hline NADPH & Glyoxylate & $1.8 \pm 0.5$ & $28.2 \pm 2.7$ & $15.7 \pm 1.5$ & $10070 \pm 2275$ \\
\hline SSA & NADPH & $6500 \pm 327$ & $18.6 \pm 3.4$ & $10.3 \pm 1.9$ & $1.6 \pm 0.2$ \\
\hline $\mathrm{NADPH}$ & SSA & $11.7 \pm 3.5$ & $15.5 \pm 1.5$ & $8.6 \pm 0.9$ & $833 \pm 183$ \\
\hline \multicolumn{6}{|l|}{ OsGLYR1 } \\
\hline Glyoxylate & NADPH & $53.2 \pm 11.1$ & $65.8 \pm 16.5$ & $33.7 \pm 7.5$ & $636 \pm 99$ \\
\hline NADPH & Glyoxylate & $8.8 \pm 2.5$ & $28.5 \pm 5.9$ & $14.2 \pm 2.9$ & $1729 \pm 201$ \\
\hline SSA & NADPH & $4003 \pm 341$ & $43.9 \pm 8.5$ & $21.9 \pm 4.2$ & $5.4 \pm 0.9$ \\
\hline NADPH & SSA & $36.2 \pm 2.1$ & $21.4 \pm 5.0$ & $10.7 \pm 2.5$ & $290 \pm 51$ \\
\hline \multicolumn{6}{|l|}{ OsGLYR2 } \\
\hline Glyoxylate & NADPH & $19.1 \pm 9$ & $18.6 \pm 7.9$ & $10.8 \pm 4.6$ & $349 \pm 16$ \\
\hline NADPH & Glyoxylate & $8.4 \pm 1.2$ & $15.3 \pm 2.9$ & $8.9 \pm 1.7$ & $1040 \pm 73$ \\
\hline SSA & NADPH & $1457 \pm 124$ & $12.4 \pm 3.5$ & $7.2 \pm 2.0$ & $5.1 \pm 1.8$ \\
\hline NADPH & SSA & $12.5 \pm 0.6$ & $11.3 \pm 0.3$ & $6.5 \pm 0.2$ & $525 \pm 40$ \\
\hline \multicolumn{6}{|l|}{ AtGLYR1 } \\
\hline Glyoxylate & NADPH & $23.2 \pm 3.2$ & $56.7 \pm 5.6$ & $28.4 \pm 2.8$ & $1259 \pm 188$ \\
\hline Glyoxylate $^{1}$ & $\mathrm{NADPH}$ & $4.5 \pm 0.9$ & $15.2 \pm 2.3$ & $13.1 \pm 1.9$ & $2870 \pm 453$ \\
\hline $\mathrm{NADPH}^{1}$ & Glyoxylate & $2.2 \pm 0.3$ & $21.6 \pm 2.4$ & $9.3 \pm 0.1$ & $4370 \pm 446$ \\
\hline $\mathrm{SSA}^{1}$ & NADPH & $870 \pm 40$ & $23.5 \pm 1.5$ & $10.1 \pm 0.4$ & $11.6 \pm 2.2$ \\
\hline $\mathrm{NADPH}^{1}$ & SSA & $2.6 \pm 0.1$ & $18.8 \pm 3.3$ & $8.1 \pm 0.0$ & $3500 \pm 208$ \\
\hline \multicolumn{6}{|l|}{ AtGLYR2 } \\
\hline Glyoxylate & NADPH & $19.3 \pm 4.0$ & $36.8 \pm 19.9$ & $18.4 \pm 10.0$ & $906 \pm 353$ \\
\hline Glyoxylate $^{2}$ & NADPH & $34.2 \pm 3.3$ & $40.6 \pm 8.7$ & $22.5 \pm 4.8$ & $660 \pm 130$ \\
\hline $\mathrm{NADPH}^{2}$ & Glyoxylate & $1.4 \pm 0.2$ & $23.0 \pm 2.2$ & $12.0 \pm 0.8$ & $8550 \pm 960$ \\
\hline $\mathrm{SSA}^{2}$ & NADPH & $8960 \pm 710$ & $30.7 \pm 4.0$ & $17.0 \pm 2.2$ & $1.9 \pm 0.3$ \\
\hline $\mathrm{NADPH}^{2}$ & SSA & $1.2 \pm 0.2$ & $19.3 \pm 1.5$ & $10.7 \pm 0.8$ & $9180 \pm 1620$ \\
\hline
\end{tabular}

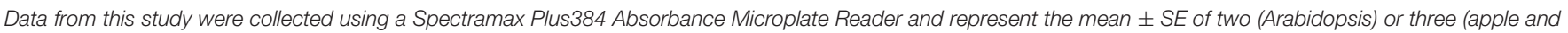

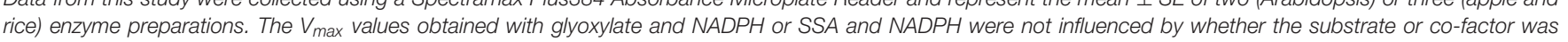

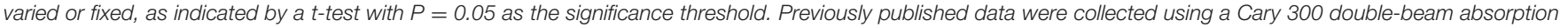
spectrophotometer (1Hoover et al., 2007a; ${ }^{2}$ Simpson et al., 2008) and represent the mean \pm SE of three enzyme preparations.

3-4 h exposure to vaporized chlorine gas ${ }^{1}$. Sterilized seeds were typically grown as a lawn on Petri plates containing half-strength Murashige and Skoog medium (Murashige and Skoog, 1962) with $0.7 \%$ agar and appropriate antibiotic for selection of transgenic plants. Following stratification of the seeds for 3 days at $4^{\circ} \mathrm{C}$, the plates were transferred to a controlled environment chamber (Enconair, Winnipeg, Canada) and supplied with a 16-h light (Sylvania Model 3500K) period at $60 \mu \mathrm{mol} \mathrm{s} \mathrm{s}^{-1}$ at $23^{\circ} \mathrm{C}$ and an 8 -h dark period at $21^{\circ} \mathrm{C}$.

Total RNA was extracted from 100 to $1000 \mathrm{mg}$ of liquid $\mathrm{N}_{2}$-frozen Arabidopsis rosette leaves (Zarei et al., 2011), rice (O. sativa L.) leaves (Brauer et al., 2011) and mature apple (Malus $\times$ domestica Borkh.) fruit (Gasic et al., 2004). RNA

${ }^{1}$ http://plantpath.wisc.edu/ afb/vapster.html was treated with DNase I using the TURBO DNA-free kit (Applied Biosystems, Austin, TX, United States) according to the manufacturer's manual. One microgram total RNA was used for first-strand cDNA synthesis with Oligo(dT)20 and Superscript III (Invitrogen, Carlsbad, CA, United States) at $50^{\circ} \mathrm{C}$ according to the manufacturer's protocol. Primers used for quantitative realtime PCR (qPCR) analyses were designed using Primer Express 3 software (Applied Biosystem, Austin TX, United States). Primers with $90-105 \%$ efficiency were selected for further analysis.

Quantitative PCR was performed according to standard methods with an iQ5 Multicolor Real-Time PCR Detection system (Bio-Rad Laboratories). The primer sequences used to determine the abundance of GLYR1, GLYR2 and housekeeping transcripts are listed in Supplementary Table S1 (RTAtGLYR1-F/R, RTAtGLYR2-F/R, RTAtEF-1-F/R, and $18 \mathrm{~S}$ rRNA- F/R). The housekeeping gene ELONGATION 
FACTOR-1 $\alpha$ (EF-1 $\alpha$, At5g60390) was chosen based on the research by Czechowski et al. (2005). Relative expression and data analysis were determined using the $2^{-\Delta \mathrm{Ct}}$ method (Livak and Schmittgen, 2001). Two technical replicates were conducted for each biological replicate, and the mean \pm SE of three biological replicates was determined for each genotype.

The presence and copy number of transgene inserts in GLYR1 overexpression ( $\mathrm{Ox}$ ) lines were determined by Southern hybridization as described by McLean et al. (2003). Genomic DNA was isolated as described by Montiel et al. (2011). About $5 \mu \mathrm{g}$ of genomic DNA was digested with NcoI, separated on a $1 \%(\mathrm{w} / \mathrm{v})$ agarose gel, and transferred to a positively charged nylon membrane (Roche Applied Science, Laval, QC, Canada). The membrane was probed, processed, and labeled bands were detected according to digoxigenin (DIG)-labeling kit protocols (Roche Applied Science). The probe was generated by PCR from the cDNA using Probe-GLYR1-F and Probe-GLYR1-R primers (Supplementary Table S1) in the presence of DIG-deoxy-uridine triphosphate. The forward primer flanked an intron/exon boundary in the GLYR1 gene to prevent GLYR1 genomic DNA amplification during probe synthesis. Hybridization was performed with a DIG-labeled probe according to the most stringent hybridization protocols of the manufacturer (Roche Applied Science). The membrane was exposed under a Fluorchem 8800 Imaging System (Alpha Innotech Inc., Miami, FL, United States) for $16 \mathrm{~min}$ to visualize labeled bands.

\section{Cloning of cDNAs Encoding Apple and Rice GLYRs and Arabidopsis GLYR2}

The predicted amino acid sequences of Arabidopsis GLYR1 (At3g25530, GenBank Acc. No. NM_113449) and GLYR2 (At1g17650, GenBank Acc. no. NM_101628) were obtained from The Arabidopsis Information Resource ${ }^{2}$. A truncated AtGLYR2 lacking its N-terminal 58 amino acid-long predicted plastid targeting sequence $($ AtGLYR2 $\triangle 58)$ was amplified from the Arabidopsis cDNA using primers VB-F4 and VB-R4 and cloned into pET15b using $N d e I$ and $B a m H I$ restriction enzymes to yield pET15b-AtGLYR $2 \Delta 58$ construct. All primer sequences used to clone the various genes are listed in Supplementary Table S1. When expressed, the truncated AtGLYR2 possesses an $\mathrm{N}$-terminal $6 \times \mathrm{His}$ tag for purification. The AtGLYR1 expression construct was made elsewhere (Hoover et al., 2007b).

Two apple GLYRs were identified in the apple genome database $^{3}$. Two products (958- and 1166-bp), designated as MdGLYR1 (GenBank Acc No. KT202799) and MdGLYR2 (GenBank Acc No. KT202800), respectively, were amplified from apple fruit cDNA cv. Empire and appropriate primers (CTF12 and CT-R12 for the MdGLYR1 gene, and CT-F13 and CT-R13 for the MdGLYR2 gene). The resulting open reading fragments (ORF) were cloned into pCR2.1-TOPO (Invitrogen). The predicted translation products are $58 \%$ identical to each

${ }^{2}$ https://www.arabidopsis.org/index.jsp

${ }^{3}$ www.rosaceae.org other. MdGLYR1 is $80 \%$ identical to AtGLYR1, and MdGLYR2 is $78 \%$ identical to AtGLYR2. The primers CT-F17 and CTR17 were used to amplify MdGLYR1 with $5^{\prime} \mathrm{NdeI}$ and $3^{\prime}$ BamHI restriction sites. TargetP $\mathrm{P}^{4}$ (v1.1; Emanuelsson et al., 2000) predicted that MdGLYR2 has an N-terminal 52 amino acid plastid targeting sequence. The primers CT-F20 and CT-R20 were used to amplify the MdGLYR2 ORF minus the sequence encoding the putative N-terminal plastid transit peptide with $5^{\prime}$ NdeI and $3^{\prime}$ BamHI restriction sites. Both sets of PCR products were digested with $\mathrm{NdeI}$ and BamHI and ligated into pET15b expression vector (Novagen, Cambridge, MA, United States) to produce pET15b-MdGLYR1 and pET15b-MdGLYR2 $\Delta 54$. When expressed, the truncated MdGLYR2 possesses an $\mathrm{N}$-terminal $6 \times$ His tag.

The AtGLYR1 and AtGLYR2 cDNAs were blasted against the rice genome annotation project ${ }^{5}$ to reveal two full-length cDNA sequences, LOC_Os02g35500 and LOC_Os01g39270, which are 81 and $65 \%$ identical to AtGLYR1 and AtGLYR2, respectively. These sequences were designated as putative OsGLYR1 and OsGLYR2, respectively. Full-length OsGLYR1 and OsGLYR2 were amplified from the rice cv. Kaybonnet cDNA using forward and reverse primers, VB-F1 and VB-R1 for OsGLYR1, and VB-F2 and VB-R2 for OsGLYR2. TargetP (v1.1 ${ }^{4}$; Emanuelsson et al., 2000) predicted that OsGLYR2 contains an N-terminal 35 amino acid-long plastid targeting sequence. The primers VB-F3 and VB-R2 were used to amplify OsGLYR2, minus the sequence encoding the protein's putative plastid transit peptide. The last two sets of PCR products were cloned into pET15b with NdeI and BamHI enzymes to yield pET15b-OsGLYR1 and pET15b-OsGLYR2 $\triangle 35$. When expressed, the truncated OsGLYRs possess an N-terminal $6 \times$ His tag for purification. All GLYR genes PCR-amplified from cDNAs were sequenced after cloning.

\section{Production, Purification and Kinetic Analysis of Recombinant Apple, Rice and Arabidopsis GLYRs}

The constructs pET15b-MdGLYR1 and pET15b-MdGLYR2 54 were individually expressed in Escherichia coli BL-21(DE3) Rosetta (pLysS) cells (Novagen) co-expressing the GroES/GroEL chaperone complex, and the resulting soluble recombinant proteins were subjected to affinity chromatography on a $\mathrm{Ni}^{2+}$ column essentially as described previously (Clark et al., 2009). Also, the pET15b-AtGLYR1, pET15b-AtGLYR2 58 , pET15b-OsGLYR1, and pET15b-OsGLYR2 35 constructs were expressed in E. coli BL-21(DE3) cells (Novagen) and the recombinant proteins purified as described in Hoover et al. (2007a). Each eluted protein was precipitated with $80 \%(\mathrm{w} / \mathrm{v})$ ammonium sulfate, stored at $-80^{\circ} \mathrm{C}$, and the pellet was resuspended, as necessary, in $100 \mu \mathrm{L}$ of reaction buffer [50 mM 4-(2-hydroxyethyl)-1-piperazineethanesulfonic acid (HEPES), 10\% sorbitol (w/v), pH 7.8 for AtGLYR1 and AtGLYR2, pH 7.5 and 7.3 for MdGLYR2 and MdGLYR2,

\footnotetext{
${ }^{4}$ http://www.cbs.dtu.dk/services/TargetP/

${ }^{5}$ http://rice.plantbiology.msu.edu/
} 
and $\mathrm{pH} 6.5$ and 7.1 for OsGLYR1 and OsGLYR2 $\triangle 35$, respectively].

Enzymatic activity was monitored as the oxidation of $\mathrm{NAD}(\mathrm{P}) \mathrm{H}$ at room temperature using a Spectramax Plus384 Absorbance Microplate Reader (Molecular Devices, Sunnyvale, CA, United States). The $250-\mu \mathrm{L}$ assay was initiated with a premade master mix of buffer, co-factor and substrate. Reaction rates were proportional to the enzyme concentrations used in the assays $(2-50 \mathrm{nM})$. The optimal $\mathrm{pH}$ for enzymatic activity at $50 \mu \mathrm{M} \mathrm{NADPH}$ and $50 \mu \mathrm{M}$ glyoxylate was determined using buffers ( $50 \mathrm{mM}$ each) with overlapping $\mathrm{pH}$ range [2-morpholinoethanesulfonic acid (MES) for $\mathrm{pH}$ 5.5-6.8; HEPES for $\mathrm{pH}$ 6.8-8.2; and $N$-tris(hydroxymethyl)methyl-4-aminobutanesulfonic acid (TABS) for $\mathrm{pH}$ 8.2-9.6]. Initially, the three buffers were tested separately for the apple isoforms, then they were combined for rice. The influence of redox ratio on the activities of MdGLYR1 and MdGLYR2 was investigated using $50 \mu \mathrm{M}$ glyoxylate, $50 \mu \mathrm{M}$ $\mathrm{NADPH}$ and $0-0.5 \mathrm{mM} \mathrm{NADP}^{+}$. The kinetic parameters $\left(V_{\max }\right.$, $\left.K_{\mathrm{m}}, k_{\text {cat }}, k_{\text {cat }} / K_{\mathrm{m}}\right)$ for the purified enzymes were determined using a mixture of the MES, HEPES, and TABS (50 mM each) at the $\mathrm{pH}$ optimum for the enzyme source under consideration, with saturating co-factor (50 $\mu \mathrm{M} \mathrm{NADPH}$ ) and varying substrate (up to $200 \mu \mathrm{M}$ glyoxylate or $10 \mathrm{mM} \mathrm{SSA}$ ) or varying co-factor (up to $100 \mu \mathrm{M} \mathrm{NADPH}$ ) and saturating substrate $(50 \mu \mathrm{M}$ glyoxylate or 3.75-10 mM SSA) as described previously (Hoover et al., 2007a). For each enzyme source the concentration of substrate or co-factor was varied to give five to six data points both above and below the $K_{\mathrm{m}}$. The dependence of enzymatic activity on $\mathrm{pH}$ or redox ratio was determined as the mean $\pm \mathrm{SD}$ of three to four technical measurements of a typical enzyme preparation (i.e., one biological replicate), whereas the kinetic parameters were expressed as the mean \pm SE of three biological replicates, each measured using four technical replicates.

\section{Generation of Arabidopsis Lines with Altered GLYR Expression}

Arabidopsis glyr1 and glyr2 single mutants (Salk_057410 and GK316D04, respectively) were twice backcrossed to the WT. Plants homozygous for glyr1 T-DNA were identified using the glyr1-RP and glyr1-LP primers for the WT allele, and LBb1.3 and glyr1-RP for T-DNA insertion (as recommended by the Salk Institute). The primers were designed using the Salk iSECT tool online software. Similarly, homozygous glyr 2 was identified using glyr2-RP and glyr2-LP primers for the WT allele, and GABIKat T-DNA border primer and glyr2-RP for the T-DNA. The double glyr1/glyr2 mutant was generated by crossing healthy plants of the homozygous glyr1 and glyr2 single mutants. With the exception of three to five closed flowers with white petals on the main shoot of the mother plant, all flowers and siliques were removed using scissors and forceps. The intact flowers on the female parent were emasculated with the aid of a dissecting microscope. Open flowers with yellow anthers were removed from the male parent and brushed against the stigmatic surface of carpels on the female parent. Female plants were labeled and covered with porous plastic bags until fruit maturity (approximately 4 weeks later). Screening of the $\mathrm{T}_{2}$ population was based on the gene-specific and T-DNA primers given above.

Arabidopsis glyr1RNAi and glyr2 RNAi lines were generated in glyr2 T-DNA and glyr1 T-DNA mutant backgrounds, respectively. To prepare hairpin RNA constructs, a 233-bp fragment (from +722 to +955 relative to the transcriptional initiation site) for AtGLYR1 and a 382-bp fragment (from +630 to +1012 ) for AtGLYR2 were each amplified by PCR from cDNA with the following primer pairs containing a LB clonase site: Clonase-GLYR1-F/Clonase-GLYR1-R and Clonase-GLYR2F/Clonase-GLYR2-R, respectively. These amplified fragments were separately cloned into the intermediate clonase vector pDONR221, followed by assembling the fragments into a gateway binary RNAi vector pB7GWIWG2 (II) by the LR clonase site reaction ${ }^{6}$ (Karimi et al., 2002). The binary vectors GLYR1-pB7GWIWG2(II) and GLYR2-pB7GWIWG2(II) were introduced into Agrobacterium tumefaciens strain EHA105 according to Hood et al. (1993). The GLYR1 and GLYR2 RNAi constructs were introduced, respectively, into the Arabidopsis glyr2 and glyr1 T-DNA mutant backgrounds using the floral dip method (Clough and Bent, 1998). Seeds were selected on solid half-strength MS medium containing $20 \mathrm{mg} \mathrm{L}^{-1}$ Basta (as a T-DNA selection marker) and $100 \mathrm{mg} \mathrm{L}^{-1}$ timentin (to prevent Agrobacterium growth), and then 14-days-old plants were transferred to Sunshine LC1 potting mix (Sun Gro Horticulture, Canada) and placed in a controlled environment growth chamber (Enconair Model GC8-2H set at $60 \mu \mathrm{mol} \mathrm{s}^{-1}$ $\mathrm{m}^{-2}$ photosynthetic photon flux density at $23^{\circ} \mathrm{C}$ for $16 \mathrm{~h}$ and no light at $21^{\circ} \mathrm{C}$ for $8 \mathrm{~h}$ ), where they were allowed to selfpollinate and mature. $T_{2}$ progenies were again selected on halfstrength MS medium containing Basta and then transferred to LC1 potting mix. Thirty seedlings were separately screened at the rosette stage for the GLYR1 and GLYR2 genes using qPCR (Supplementary Figure S1); the primer sets are given in Supplementary Table S1. Seeds of selected lines were collected for further experiments.

For generation of AtGLYR1 overexpression (Ox) lines, the full-length cDNA sequence for AtGLYR1 was amplified using SpeI-GLYR1-F and SpeI-GLYR1-R primers and cloned into a prepared pMdM7 binary vector ( $\mathrm{Ni}$ et al., 1995) and transformed into A. tumefaciens strain LB4404. Plant transformation, transformant screening, tissue culture and growth conditions were similar to above, except that seed were selected on medium containing $50 \mathrm{mg} \mathrm{L}^{-1}$ kanamycin. The three transgenic lines that were chosen for further analysis had two to three times the GLYR1 transcript level of the WT (Supplementary Figure S2). Assays of GLYR activity in desalted cell-free leaf extracts with $50 \mu \mathrm{M}$ glyoxylate and NADPH (Simpson et al., 2008) revealed that two of the three lines had $70-90 \%$ higher activity than the WT. Southern blot analysis revealed weak signals, if at all, in the WT lane, perhaps as a results of only partial binding between the unprocessed endogenous gene and the probe. However, it was clear that the two lines with highest GLYR activity carried two to three copies, of the transgene. The line with the highest activity

\footnotetext{
${ }^{6}$ http://www.psb.ugent.be/gateway/
} 
and lowest transgene copy number was selected for further experimentation.

\section{Chilling Phenotype of Arabidopsis Lines with Altered GLYR Expression}

In preliminary chilling trials, five sterilized seeds from the Arabidopsis WT and each of the GLYR1 Ox, glyr1/2 and glyr1/2RNAi lines were sown along the center of $14-\mathrm{cm}$ Petri plates containing half-strength MS medium with $0.6 \%(\mathrm{w} / \mathrm{v})$ agar, $30 \mathrm{~g} \mathrm{~L}^{-1}$ sucrose, $1 \mathrm{mM}$ MES ( $\mathrm{pH}$ 5.8) and SSA or GHB (0-3 mM) and then subjected to a stratification regime ( 3 days, $4^{\circ} \mathrm{C}$, dark). Thereafter, the plates were stored vertically in a tissue culture chamber under 12 -h period at $22^{\circ} \mathrm{C}$ for 12 days or $10^{\circ} \mathrm{C}$ for 27 days (photosynthetic flux density of $60 \mu \mathrm{mol} \mathrm{m}^{-2} \mathrm{~s}^{-1}$ ). The experimental design was completely randomized and comprised of three plate replicates for each treatment.

In follow up trials, sterilized seeds from the WT and glyr1/2 and GLYR1 Ox lines were sown as a lawn on 150-mm Petri plates containing half-strength MS medium with $0.6 \%(\mathrm{w} / \mathrm{v})$ agar, $30 \mathrm{~g} \mathrm{~L}^{-1}$ sucrose, and $1 \mathrm{mM} \mathrm{MES} \mathrm{(pH} \mathrm{5.8),} \mathrm{subjected}$ to a stratification regime ( 3 days, $4^{\circ} \mathrm{C}$, dark), and then placed in a tissue culture chamber $\left(22^{\circ} \mathrm{C}, 14 \mathrm{~h}\right.$ light $/ 18^{\circ} \mathrm{C}, 10 \mathrm{~h}$ dark, photosynthetic flux density of $120 \mu \mathrm{mol} \mathrm{m}^{-2} \mathrm{~s}^{-1}$ ) for 8 days. Seedlings from all three genotypes were placed along the center of individual $14-\mathrm{cm}$ plates containing the same medium supplemented with glyoxylate $(0-2 \mathrm{mM})$ or SSA $(0-3 \mathrm{mM})$ and the primary root apex was noted on the exterior surface of the plate. Then the plates were stored vertically at $10^{\circ} \mathrm{C}$ for another 8 days and photographed. The gain in root growth was estimated using ImageJ software ${ }^{7}$. The experimental design was completely randomized and comprised of 10 plate replicates for each treatment.

\section{Distribution of GLYR Activity in Cytosolic, Plastidial, and Mitochondrial Fractions from Arabidopsis}

Crude homogenates of rosette leaf tissue from 4-week-old Arabidopsis WT or glyr1 mutant (grown as described above), were prepared using the extraction medium $[0.3 \mathrm{M}$ sucrose, $25 \mathrm{mM} \mathrm{Na} \mathrm{P}_{2} \mathrm{O}_{7}, 2 \mathrm{mM}$ sodium ethylenediaminetetraacetate, $10 \mathrm{mM} \mathrm{KH}_{2} \mathrm{PO}_{4}, 1 \%$ (w/v) polyvinylpyrrolidone- $40,1 \%$ bovine serum albumin] described by Taylor et al. (2014). Then the homogenates were sonicated for $10 \mathrm{~s}$ using a sonic dismembrator (Fisher Scientific, Model 120), and pelleted by centrifugation. The supernatants were desalted using Econo-Pac 10DG columns (Bio-Rad) and assayed for GLYR activity with $50 \mu \mathrm{M}$ glyoxylate and NADPH. Intact mitochondria were also isolated from $50 \mathrm{~g}$ of homogenized rosette tissue of the glyr1 mutant grown under a $23^{\circ} \mathrm{C} 11$-h light $\left(120 \mu \mathrm{mol} \mathrm{m}^{-2} \mathrm{~s}^{-1}\right) / 19^{\circ} \mathrm{C} 13$-h dark regime according to Taylor et al. (2014). Briefly, the crude homogenate was differentially centrifuged to give an organelle suspension, which was then applied to a linear polyvinylpyrrolidone-40 gradient $(0-4.4 \% \mathrm{v} / \mathrm{v})$ in $28 \%(\mathrm{w} / \mathrm{v})$ Percoll and centrifuged at $40,000 \times g$ for $40 \mathrm{~min}$. This enabled recovery of a white/pale

${ }^{7}$ http://rsbweb.nih.gov/ij/ brown mitochondrial band toward the bottom of the gradient (separated from plastid thylakoid and peroxisomal fractions), which was then concentrated and washed repeatedly using differential centrifugation. Aliquots of the organelle suspension and purified mitochondria fractions were sonicated, pelleted by centrifugation, and desalted as described above. GLYR activity was assayed with $50 \mu \mathrm{M}$ glyoxylate and NADPH, and mitochondrial fumarase and plastid phosphoribulokinase were assayed as described previously (Taylor et al., 2014), with the exception that the reaction volume was $250 \mu \mathrm{L}$ and the wavelength used for the fumarase assay was $240 \mathrm{~nm}$ (Puchegger et al., 1990), rather than $340 \mathrm{~nm}$ as given.

\section{RESULTS}

\section{Characterization of Recombinant Apple, Rice, and Arabidopsis GLYRs}

The predicted $\mathrm{N}$-terminal targeting presequences in GLYR2s from apple, rice, and Arabidopsis (Brikis et al., 2017) were removed and the resulting truncated sequences (i.e., $M d$ GLYR2 $\Delta 54$, OsGLYR2 $\Delta 35$, and AtGLYR2 $\Delta 58$ ), as well as the corresponding full-length GLYR1s from the same three plant species (i.e., MdGLYR1, OsGLYR1, and AtGLYR1), were individually expressed in E. coli. This allowed for the recovery of a significant portion of the recombinant GLYR2 proteins, similar to the GLYR1 proteins, in the corresponding soluble fraction (Supplementary Figure S3). In all fractions eluted from $\mathrm{Ni}^{2+}$-affinity columns, the recombinant protein was purified to near homogeneity. Predicted protein masses for MdGLYR1, MdGLYR2 $\Delta 54, \quad$ OsGLYR1, OsGLYR2 $\Delta 35$, AtGLYR1, and AtGLYR2 $\triangle 58$ were $31.8,33.1,30.5,31.4$, 30.7 , and $33.2 \mathrm{kDa}$, respectively. The mass of recombinant AtGLYR2 $\Delta 58$ appeared slightly larger than predicted. The scientific literature contains many examples of cytosolic proteins that migrate during SDS polyacrylamide electrophoresis at rates that are inconsistent with their molecular mass (see Shi et al., 2012). While such "gel shifting" could be caused by single amino acid substitutions, we repeatedly cloned and sequenced the gene and prepared the recombinant AtGLYR2 $\Delta 58$ protein with similar results. It is possible that interaction between SDS and the mutant protein is modified by the presence of the N-terminal $6 \times$ His motif. The activities of MdGLYR1and OsGLYR1 were maximal at $\mathrm{pH} 6.8$ and 6, respectively, although both enzymes retained at least half of maximal activity over the $\mathrm{pH}$ range of 5.5-7. The maximal activities of MdGLYR2 and OsGLYR2 were found to be at approximately $\mathrm{pH} 6.8$ and at least $50 \%$ of maximal activity was retained in the $\mathrm{pH}$ range of $6-8$ (Figure 1).

In the present study, enzymatic activity for the various recombinant proteins was determined using a microplate reader. A preliminary study of glyoxylate-dependent activity in rice GLYR1 revealed that 50 and $100 \mu \mathrm{M}$ NADPH gave approximately 4.5 times the activity with corresponding levels of NADH (data not shown); therefore, detailed NADH kinetics for both rice and apple GLYRs were not determined here. The kinetic data for the apple and rice proteins with NADPH as the co-factor 

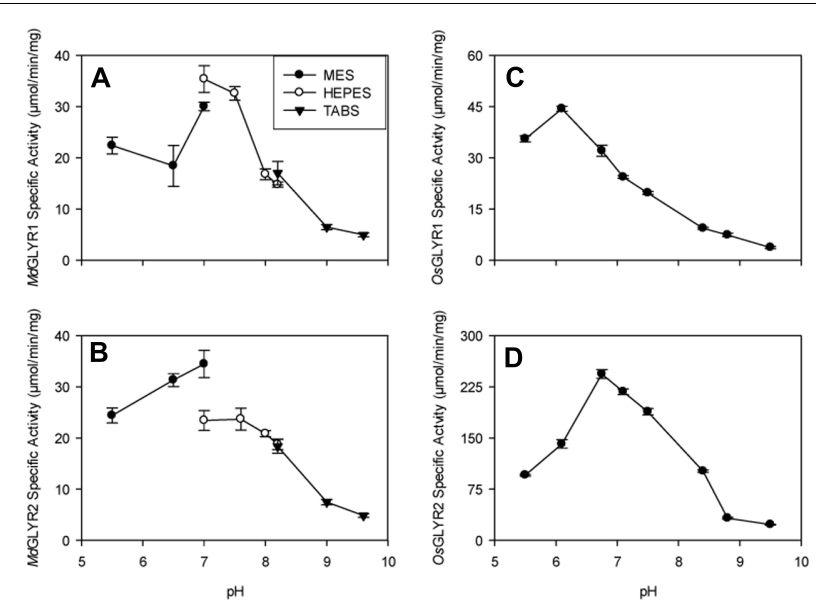

FIGURE 1 | Dependence of recombinant apple and rice GLYR activities on $\mathrm{pH}$. The left and right panels, represent apple (A,B) and rice (C,D) GLYRs, respectively, whereas the upper and lower panels represent GLYR1s $(\mathbf{A}, \mathbf{C})$ and GLYR2s (B,D), respectively. The data, expressed as specific activity

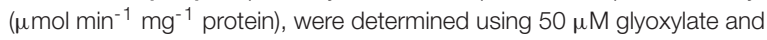
$\mathrm{NADPH}$ in thee buffers (50 $\mathrm{mM}$ each): 2-morpholino-ethanesulfonic acid, 4-(2-hydroxyethyl)-1-piperazineethanesulfonic acid and

$\mathrm{N}$-tris(hydroxymethyl)methyl-4-aminobutanesulfonic acid either separately

$\mathbf{( A , B )}$ or together $\mathbf{( C , D )}$. Each datum represents the mean $( \pm S D)$ of three technical measurements of a typical enzyme preparation.

represent the mean $( \pm S E)$ of three replicate preparations, and the $V_{\max }$ values obtained with glyoxylate or SSA were not significantly influenced by whether the substrate or co-factor was varied or fixed $(P>0.05, t$-test) (Table 1). Glyoxylatedependent kinetics with NADPH were also determined here for the AtGLYR1 and the AtGLYR2 using the microplate reader, so that direct comparisons could be made with published values obtained with the use of a Cary 300 spectrophotometer. Overall, the catalytic efficiencies $\left(k_{\text {cat }} / K_{\mathrm{m}}\right)$ of the apple and rice GLYRs, like those for the Arabidopsis GLYRs (Hoover et al., 2007a; Simpson et al., 2008), were within the same order of magnitude for each substrate, and the $K_{\mathrm{m}}$ values for glyoxylate and NADPH were in the micromolar range, whereas the $K_{\mathrm{m}}$ values for SSA were in the millimolar range (see Table 1 and Supplementary Figures S4-S6). For all GLYRs, the highest catalytic efficiencies were observed for NADPH, mostly at fixed glyoxylate concentrations, followed by glyoxylate at fixed NADPH concentrations, whereas catalytic efficiencies for SSA were 0.2 to $1.4 \%$ of those for glyoxylate (Table 1). Overall, the catalytic efficiencies of GLYR1 and GLYR2 for glyoxylate or SSA in the NADPH-dependent reaction ranged approximately three- to four-fold only across the species compared here, and there were no identifiable catalytic differences between the GLYR1 and GLYR2 isoforms, indicating that all GLYRs prefer glyoxylate over SSA, and have a high affinity for their co-substrate NADPH. The activities of MdGLYR1 and MdGLYR2 displayed inhibitory responses to an increasing $\mathrm{NADP}^{+} / \mathrm{NADPH}$ ratio (Figure 2 ), and their reaction rates were reduced by half with an $\mathrm{NADP}^{+} / \mathrm{NADPH}$ ratio of 5 .

\section{Phenotypic Response to Chilling of Various GLYR Lines Supplied with Exogenous Glyoxylate, Succinic Semialdehyde, or $\gamma$-Hydroxybutyrate}

To investigate whether GLYR activity is linked to a phenoptypic response to chilling, seeds of Arabidopsis WT, GLYR1 Ox, glyr1/2 and glyr1/2-RNAi were sown directly on agar medium and grown at $22^{\circ} \mathrm{C}$ or $10^{\circ} \mathrm{C}$ in separate tissue culture chambers. At $22^{\circ} \mathrm{C}$, the early growth of the different genotypes was similar in the absence or presence of added SSA or GHB up to 12 days (data not shown). The early growth of the genotypes at $10^{\circ} \mathrm{C}$ was also similar in the absence of glyoxylate or GHB after 27 days (Figures 3A,E). However, when SSA or GHB (up to $3 \mathrm{mM}$ each) was added to the medium, a differential response was observed among the genotypes at $10^{\circ} \mathrm{C}$. That is, increasing concentrations of SSA progressively inhibited growth and development (Figures 3B-D). At $1 \mathrm{mM}$ SSA, the inhibition was greater with glyr1/2-RNAi and glyr1/2 than the WT and GLYR1 Ox, and purple tinging of the leaves was repeatedly observed in the WT (Figure 3B). At $2 \mathrm{mM} \mathrm{SSA}$, radicle development in both glyr1/2-RNAi and glyr1/2 was halted, and shoot production was entirely absent (Figures 3C,D). Higher magnification observations from a replicate experiment indicated that $2 \mathrm{mM}$ SSA stunted radicle growth in all four lines, and confirmed that shoot and leaf development was hindered in glyr1/2-RNAi and glyr1/2 (Figures 3C,D). In general, the plantlets were more tolerant to GHB than SSA. Root length was reduced with 2 and $3 \mathrm{mM} \mathrm{GHB}$, and shoot reduction and yellowing were particularly evident at $3 \mathrm{mM} \mathrm{GHB}$; notably, the WT and GLYR1 Ox line were more sensitive to GHB than glyr1/2 and glyr1/2-RNAi (Figures 3E-G).

To further investigate whether GLYR activity could be linked to a phenotypic response, Arabidopsis WT, and transgenic GLYR1 Ox and glyr1/2 plantlets were transferred to a chilling temperature of $10^{\circ} \mathrm{C}$ for an 8 -days period in the presence of glyoxylate or SSA. In the absence of glyoxylate, all genotypes displayed a similar gain in root length; however, the addition of glyoxylate generally decreased this gain (Figure 4A). Notably, the GLYR1 Ox line gained more root length than WT and glyr1/2 mutant plants with $1 \mathrm{mM}$ glyoxylate, whereas GLYR1 Ox gained more root length than glyr1/2 but not the WT in the presence of $2 \mathrm{mM}$ glyoxylate (Figure 4B). We were unable to demonstrate the same differential response to SSA using this experimental design (data not shown).

\section{Subcellular Localization of GLYR Activity in Arabidopsis}

As expected, AtGLYR1 expression in leaves of the Arabidopsis glyr1 mutant was not detectable, and the total GLYR activity in crude tissue homogenates was markedly less than that in the WT (Figures 5A,B), indicating that cytosolic AtGLYR1 and plastidial/mitochondrial AtGLYR2 could be responsible for approximately 85 and $15 \%$ of the total GLYR activity, respectively, in leaves. To further assess whether AtGLYR2 is located in mitochondria, as well as plastids, mitochondria were purified from a leaf organelle suspension from the glyr1 

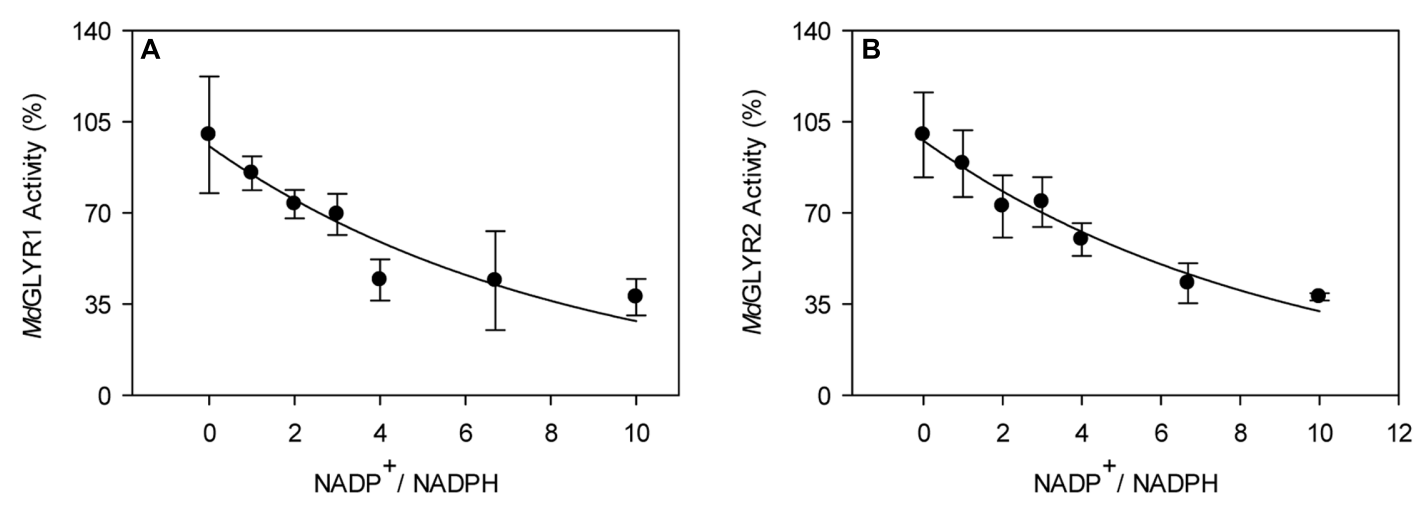

FIGURE 2 | Dependence of recombinant apple GLYR activities on NADP+/NADPH ratio. The activities of MdGLYR1 (A) and MdGLYR2 54 (B) were determined using $50 \mu \mathrm{M}$ glyoxylate and $\mathrm{NADPH}$, and increasing concentrations of NADP ${ }^{+}$. Data represent the mean $\pm \mathrm{SD}$ of four technical measurements of a typical enzyme preparation.

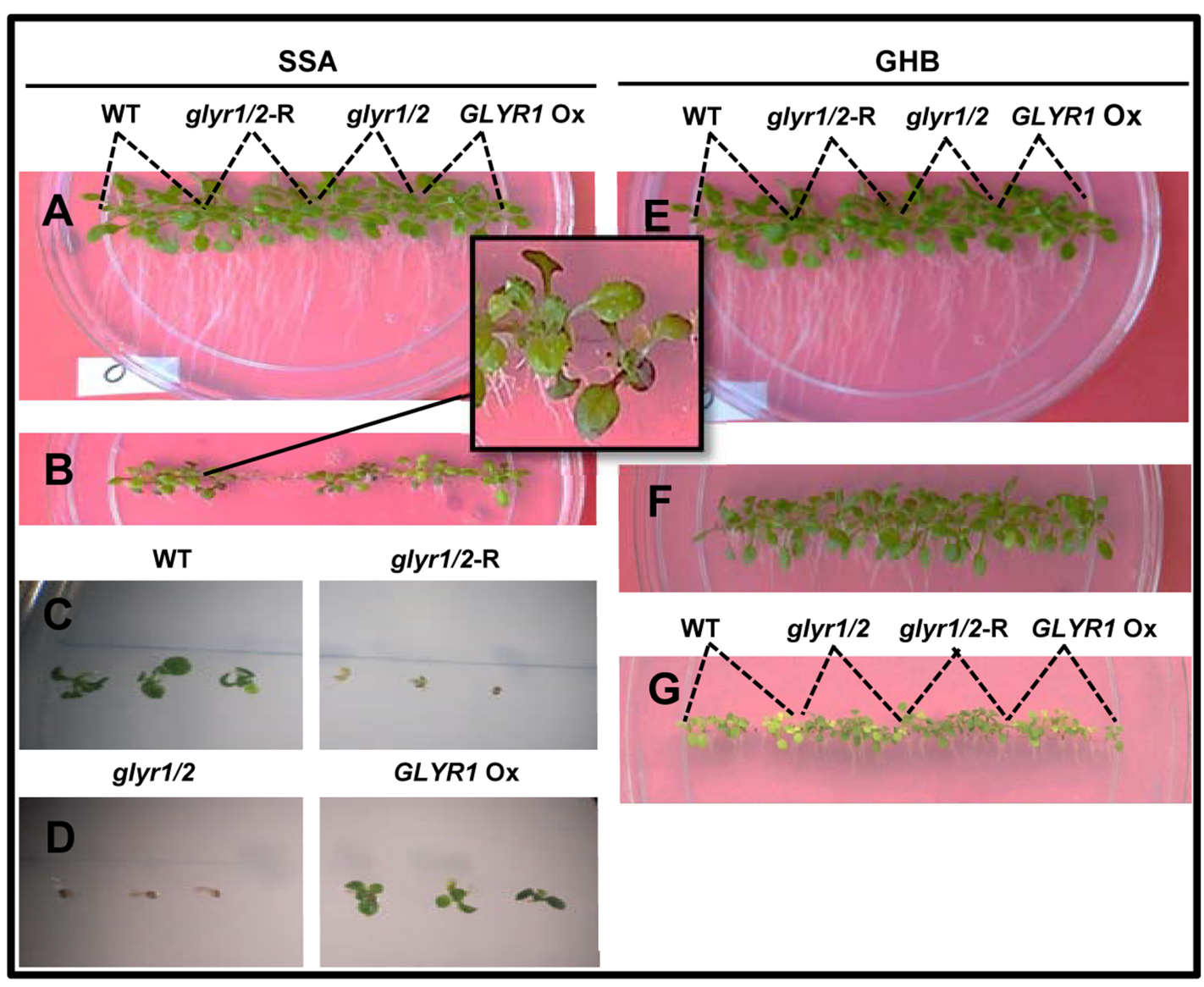

FIGURE 3 | Impact of Arabidopsis genotype on the early phenotypic response to succinic semialdehyde or $\gamma$-hydroxybutyrate under chilling stress. Seeds of wild-type (WT) plants and glyr1/2-RNAi, glyr1/2, and GLYR1 Ox were sown on plates containing half-strength MS medium with up to 3 mM SSA or GHB and grown at $10^{\circ} \mathrm{C}$ for 27 days. Levels of SSA or GHB are 0 (A,E), 1 (B), 2 (C,D,F), and 3 (G) mM.

mutant. The organelle suspension and purified mitochondria were assayed for marker enzymes and GLYR activity. As shown in Figure 5C, the activities of plastidial phosphoribulokinase, mitochondrial fumarase and GLYR were present in the organelle suspension. Phosphoribulokinase activity was not detectable in the purified mitochondria, confirming that this fraction was essentially free of plastid contamination and, hence, plastidial AtGLYR2. The specific activity of 

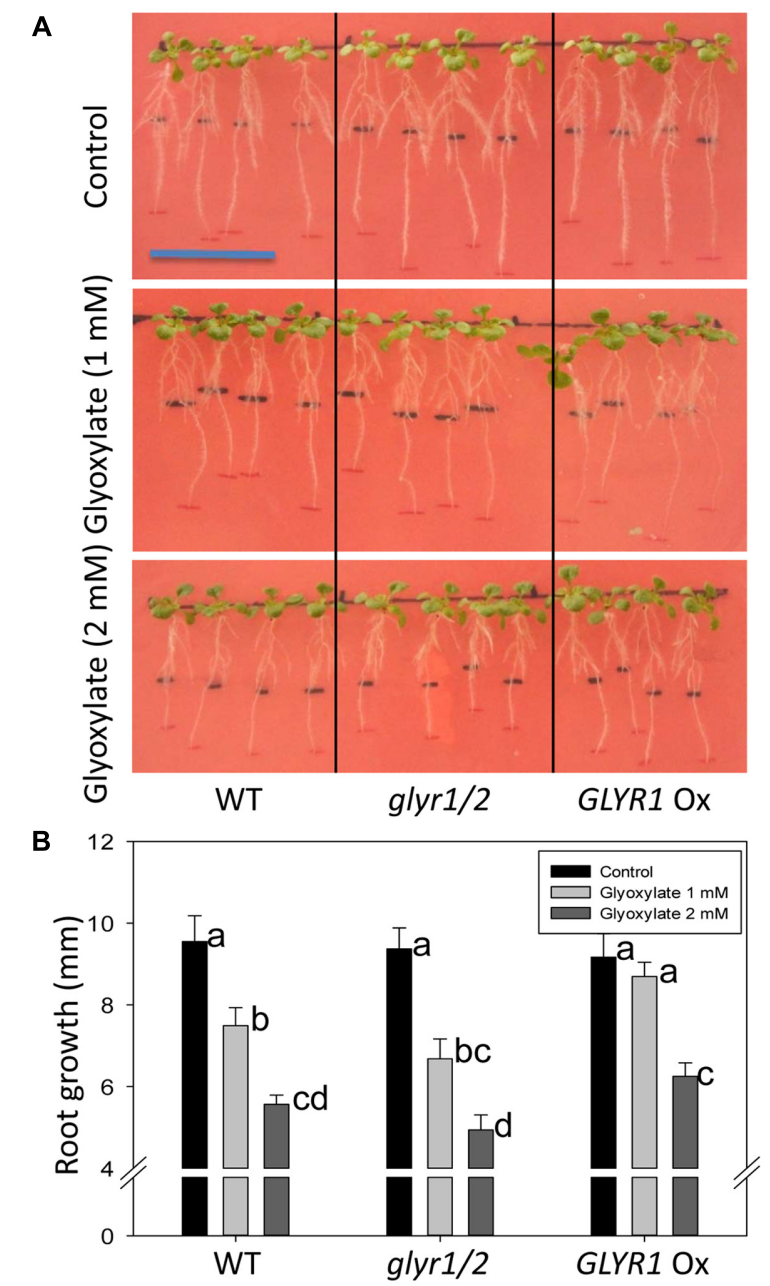

FIGURE 4 | Impact of Arabidopsis genotype on the response of root growth to glyoxylate under chilling stress. Seeds of WT, glyr1/2 and GLYR1 Ox were sown on plates containing half-strength MS medium and grown at ambient temperature for 8 days. Then the plantlets were transferred to new agar plates containing 0 (control), 1 or $2 \mathrm{mM}$ glyoxylate, as indicated on the $y$-axis, grown at $10^{\circ} \mathrm{C}$ for another 8 days, and then the gain in root length was determined (A). Results are the least squared means \pm SE of measurements from 10 plates (three plants per plate) estimated following two-way analysis of variance (ANOVA) performed in PROC MIXED procedure in SAS with $P=0.05$ as the significance threshold. (B) Error bars sharing the same letter are not significantly different.

fumarase was enriched approximately 53-fold in the purified mitochondria, compared to the organelle suspension, whereas the specific activity of GLYR was enriched approximately 2.1fold. These findings lend further support for the notion that AtGLYR2 is indeed localized in mitochondria, as well as plastids.

\section{DISCUSSION}

The recombinant apple and rice GLYR1s and GLYR2s investigated here were highly active with glyoxylate and
$\mathrm{NADPH}$ over a relatively broad $\mathrm{pH}$ range from slightly acidic to slightly basic, regardless of whether the different $\mathrm{pH}$ buffers were combined or tested separately in the assay mixtures (Figure 1). These results are in agreement with previous studies of the recombinant Arabidopsis GLYRs (Hoover et al., 2007b; Simpson et al., 2008), and the purified spinach enzyme (Kleczkowski et al., 1986). Our kinetic analyses showed that recombinant GLYRs from the monocotyledonous rice, as well as the dicotyledonous apple and Arabidopsis, behaved similarly with respect to their catalytic efficiencies (Table 1), probably because of their conserved active site residues and NADPH-binding sequence (Hoover et al., 2013; Brikis et al., 2017). The $K_{\mathrm{m}}$ values for glyoxylate and SSA were 5-53 $\mu \mathrm{M}$ and $0.8-9 \mathrm{mM}$, respectively, with NADPH as the co-factor (Table 1), whereas the $K_{\mathrm{m}}$ for glyoxylate was $60 \mu \mathrm{M}$ for the purified spinach enzyme (Kleczkowski, 1995). Thus, it can be concluded that all plant GLYRs have a preference for glyoxylate over SSA. There are few reliable data on the pool sizes of glyoxylate and SSA in plants, perhaps in part because of their propensity to form adducts (Nikiforova et al., 2014; also see references therein). The level of glyoxylate in rice seedlings is $0.27 \mu \mathrm{mol} \mathrm{g} \mathrm{g}^{-1}$ fresh mass (FM) (Yu et al., 2010) or $0.27 \mathrm{mM}$ (assuming $1 \mathrm{~g}$ FM equals $1 \mathrm{~mL} \mathrm{H}_{2} \mathrm{O}$ ), which is within the micromolar range known to inhibit photosynthesis in intact chloroplasts (Campbell and Ogren, 1990). The product of glyoxylate reduction, glycolate, is known to accumulate in rice seedlings germinated under hypoxic conditions (Narsai et al., 2009). SSA levels are low $(10-16 \mu \mathrm{M})$ in various parts of Arabidopsis plants (Palanivelu et al., 2003; Toyokura et al., 2011). However, accumulation of $\mathrm{GHB}$, the product of SSA reduction, increases in Arabidopsis and tobacco plants from approximately $0.04 \mu \mathrm{mol} \mathrm{g}^{-1} \mathrm{FM}$ to $0.12-2.4 \mu \mathrm{mol} \mathrm{g}^{-1} \mathrm{FM}$ with the imposition of salinity, submergence, heat and chilling stresses (Allan et al., 2008), and submergence-induced GHB accumulation is markedly reduced in Arabidopsis glyr1 and glyr2 mutants (Allan et al., 2012).

The $K_{\mathrm{m}} \mathrm{s}$ for $\mathrm{NADPH}$ were $2-9 \mu \mathrm{M}$ with the recombinant apple, rice, and Arabidopsis GLYRs (Table 1), and 3-6 $\mu \mathrm{M}$ for the purified spinach enzyme (Kleczkowski et al., 1986; Kleczkowski, 1995). NADPH was preferred over NADH as the co-factor for both OsGLYR1 and AtGLYR1 (see Results; Hoover et al., 2007a), results in general agreement with those for the purified spinach enzyme (note: $K_{\mathrm{m}} \mathrm{s}$ for glyoxylate and $\mathrm{NADH}$ are 0.3 and $1.1 \mathrm{mM}$, respectively, in combination with a lower estimated $V_{\max }$, Kleczkowski, 1995). Our previous results indicated that the $K_{\mathrm{i}}$ for $\mathrm{NADP}^{+}$, a competitive inhibitor of the glyoxylate- and SSA-dependent reactions, is 3.1-9.5 $\mu \mathrm{M}$ for AtGLYR1 (Hoover et al., 2007b). This is much lower than the corresponding value $\left(K_{\mathrm{i}}=60 \mu \mathrm{M}\right)$ for the purified spinach enzyme (Kleczkowski, 1995), and seemingly at odds with the slight inhibition of apple GLYRs by $\mathrm{NADP}^{+}$(i.e., approximately 50\% inhibition with a fivefold increase in $\mathrm{NADP}^{+}$, Figure 2). The estimated ratios of NADPH:NADP ${ }^{+}$in intact leaves of Arabidopsis (Allan et al., 2008, 2012), cytosol of spinach, barley, and pea leaves (Heineke et al., 1991; Wigge et al., 1993; Kleczkowski, 1995; Igamberdiev and Gardeström, 2003), and spinach chloroplasts (Heineke et al., 1991) are approximately 2, 1-4, and 0.5, 


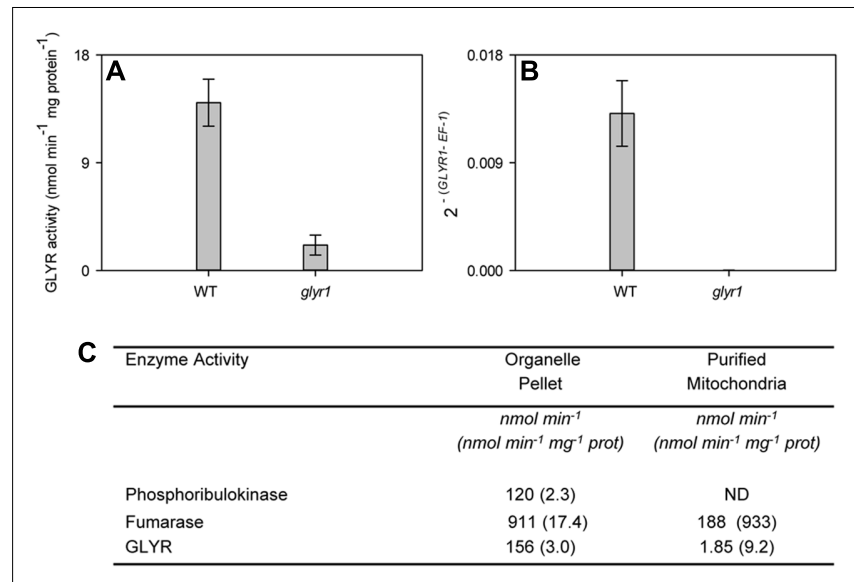

FIGURE 5 | Mitochondrial localization of GLYR2 activity in rosette leaf tissue from Arabidopsis. Total GLYR activity (A) and GLYR1 expression (B) in WT and glyr1 knockout mutant. Data represent the mean \pm SE of three biological replicates. GLYR activity (total per fraction, or protein bases) in the organelle suspension and purified mitochondria from glyr1 mutant (C). Data represent a preparation of $50 \mathrm{~g}$ of rosette leaf tissue; ND, not detected. Similar results were obtained with a replicate preparation.

respectively. Thus, it can be concluded that all plant GLYRs have a high affinity for NADPH, and $\mathrm{NADP}^{+}$is not likely to be an important regulator of GLYR activity under ambient conditions, as suggested earlier (Kleczkowski, 1995). Notably, the estimated $\mathrm{NADPH} / \mathrm{NADP}^{+}$ratios in Arabidopsis and tobacco leaves have been shown to increase by 0.5 - to 4 -fold with submergence, heat and chilling stresses (Allan et al., 2008). In the absence of applied stress, the NADPH/NADP ${ }^{+}$ratio in an NAD KINASE1 Ox line of Arabidopsis is increased by threefold, and there is a corresponding increase in GHB accumulation (Allan et al., 2012).

Taken together, these findings are in agreement with the suggestion that GLYR activities are stimulated by stress, likely in response to the elevated supply of one or both substrates, glyoxylate and SSA, as well as the co-factor NADPH (Hoover et al., 2007a; Allan et al., 2008, 2012), despite the low affinity of GLYRs for SSA and the low tissue levels of SSA under ambient conditions. Mekonnen and Ludewig (2016) have shown the growth of both glyr1/2 double mutants and WT plants is more sensitive to exogenous SSA than GHB at ambient temperature. Since chilling is known to cause the accumulation of both GHB and its precursor GABA in Arabidopsis within hours of exposure, and greatly enhance the leaf NADPH:NADP ${ }^{+}$ratio (Allan et al., 2008), we predicted that chilling would generate a differential phenotype among the GLYR genotypes. Indeed, plantlets of the various genotypes did display a qualitative difference in the early growth response when grown on increasing levels of exogenous SSA or GHB at $10^{\circ} \mathrm{C}$, but not $22^{\circ} \mathrm{C}$ (Figure 3). It was also possible to quantitatively demonstrate that the root growth of established plantlets of the various genotypes responded differentially to exogenous glyoxylate (but not SSA) with chilling (Figure 4). Since roots are unlikely to generate photorespiratory glyoxylate, these findings suggest that GLYRs function in the reduction of toxic aldehydes, including glyoxylate from multiple metabolic pathways (e.g., glyoxylate from non-photorespiratory serine synthesis, fatty acid catabolism, interconversion of organic acids, purine catabolism (see Introduction for citations), in plants subjected to chilling stress.

The reduction of glyoxylate can also be catalyzed by various hydroxypyruvate reductases (Kleczkowski et al., 1991; Timm et al., 2011). For example, in Arabidopsis, there are three isoforms: a peroxisomal HPR1 with a preference for $\mathrm{NADH}$ and hydroxypyruvate over NADPH and glyoxylate, respectively; a cytosolic HPR2 with a preference for NADPH over $\mathrm{NADH}$, but similar preference for hydroxypyruvate and glyoxylate; and, a plastidial HPR3 with a preference for $\mathrm{NADPH}$ and glyoxylate over NADH and hydroxypyruvate, respectively (Timm et al., 2011). Our research has used transient and stable expression systems to unambiguously demonstrate that apple, rice, and Arabidopsis GLYR1s are localized to the cytosol, whereas the corresponding GLYR2s are localized in both plastids and mitochondria (Ching et al., 2012; Brikis et al., 2017). Here, approximately $85 \%$ of the total glyoxylate-reducing activity in Arabidopsis leaf extracts was lacking in the glyr1 mutant (Figure 5), indicating that GLYR1, rather than HPR2, is responsible for the majority of the cytosolic activity. Furthermore, the recovery of glyoxylatereducing activity in purified mitochondria from the glyr1 mutant, free from cytosolic GLYR1, plastidial GLYR2 (Figure 5) or plastidial HPR3 (Timm et al., 2011) contamination, provided in planta support for the dual targeting of GLYR2. The percentage distribution of GLYR2 between mitochondria and plastids remains uncertain, although oxalate may be a useful tool to distinguish between plastidial GLYR2 and HPR3 activities (Kleczkowski et al., 1991). Early studies, using the photosynthesizing protist Euglena gracilis, reported the presence of NADPH-dependent GLYR activity in the intermembrane space of mitochondria, which constitutes approximately $2 \%$ of total mitochondrial protein (Yokota and Kitaoka, 1979; Yokota et al., 1985). The $K_{\mathrm{m}}$ values for NADPH and glyoxylate for this enzyme are in the low micromolar range and the $\mathrm{pH}$ optimum is 6.45 (Yokota et al., 1985), which are similar to our findings with GLYRs from Arabidopsis, apple and rice (Table 1).

In summary, the ability of GLYRs to promiscuously catalyze the reduction of SSA, as well as glyoxylate, appears to have physiological implications for the plant response to chilling conditions and could be relevant to other abiotic stresses. The generation of SSA is generally restricted to mitochondria with the catabolism of GABA (Shelp and Zarei, 2017; see references therein), whereas glyoxylate can be derived from multiple biochemical processes and subcellular compartments. With abiotic stresses, the detoxification of SSA could be diverted from the generation of succinate to GHB as SSA dehydrogenase activity becomes restricted with the accumulation of NADH (António et al., 2016). With the exception of hypoxia, abiotic stresses generally cause stomatal closure and result in corresponding increases in Rubisco oxygenase activity (Allan et al., 2009). This could increase the production and levels of glyoxylate, 
so that its detoxification could require capacity in addition to the photorespiration-associated transaminase activities (i.e., serine/asparagine:glyoxylate and glutamate:glyoxylate transaminases) (Peterhansel et al., 2010; Modde et al., 2017): reduction to glycolate (GLYR and HPR); decarboxylation to formate, and, oxidation to oxalate (Igamberdiev and Eprintsev, 2016; see references therein). On the other hand, with hypoxia glycolate oxidase and glycine decarboxylase activities could be inhibited (Allan et al., 2009), and detoxification of non-photorespiratory sources of glyoxylate could occur via a combination of reduction (GLYR and HPR), GABA transamination, and decarboxylation and oxidation activities.

\section{AUTHOR CONTRIBUTIONS}

BS conceived and supervised the project. AZ, CB, VB, and GC conducted the experiments and data analysis. JS prepared and identified the Arabidopsis GLYR1 overexpression lines. JD and GB discussed the project. AZ, CB, GB, and BS wrote and/or edited the manuscript. All authors read and approved the final manuscript.

\section{REFERENCES}

Allan, W. L., Breitkreuz, K. E., Waller, J. C., Simpson, J. P., Hoover, G. J., Rochon, A., et al. (2012). Detoxification of succinic semialdehyde in Arabidopsis glyoxylate reductase and NAD kinase mutants subjected to submergence stress. Botany 90, 51-61. doi: 10.1139/b11-083

Allan, W. L., Clark, S. M., Hoover, G. J., and Shelp, B. J. (2009). Role of plant glyoxylate reductases during stress: a hypothesis. Biochem. J. 423, 15-22. doi: 10.1042/BJ20090826

Allan, W. L., Peiris, C., Bown, A. W., and Shelp, B. J. (2003). Gammahydroxybutyrate accumulates in green tea and soybean sprouts in response to oxygen deficiency. Can. J. Plant Sci. 83, 951-953. doi: 10.4141/P03-085

Allan, W. L., Simpson, J. P., Clark, S. M., and Shelp, B. J. (2008). $\gamma$-Hydroxybutyrate accumulation in Arabidopsis and tobacco plants is a general response to abiotic stress: putative regulation by redox balance and glyoxylate reductase isoforms. J. Exp. Bot. 59, 2555-2564. doi: 10.1093/jxb/ern122

António, C., Päpke, C., Rocha, M., Diab, H., Limami, A. M., Obata, T., et al. (2016). Regulation of primary metabolism in response to low oxygen availability as revealed by carbon and nitrogen isotope redistribution. Plant Physiol. 170, 43-56. doi: 10.1104/pp.15.00266

Bauwe, H., Hagemann, M., and Fernie, A. R. (2010). Photorespiration: players, partners and origin. Trends Plant Sci. 15, 330-336. doi: 10.1016/j.tplants.2010. 03.006

Biswas, M. D., and Mano, J. (2015). Lipid peroxide-derived short-chain carbonyls mediate hydrogen peroxide-induced and salt-induced programmed cell death in plants. Plant Physiol. 168, 885-898. doi: 10.1104/pp.115.256834

Bouché, N., Fait, A., Bouchez, D., Moller, G. G., and Fromm, H. (2003). Mitochondrial succinic-semialdehyde dehydrogenase of the $\gamma$-aminobutyrate shunt is required to restrict levels of reactive oxygen intermediates in plants. Proc. Natl. Acad. Sci. U.S.A. 100, 6843-6848. doi: 10.1073/pnas. 1037532100

Bown, A. W., and Shelp, B. J. (1997). The metabolism and functions of gammaaminobutyric acid. Plant Physiol. 115, 1-5. doi: 10.1104/pp.115.1.1

Brauer, E. K., Rochon, A., Bi, Y., Bozzo, G. G., Rothstein, S. J., and Shelp, B. J. (2011). Reappraisal of nitrogen use efficiency in rice overexpressing glutamine synthetase1. Physiol. Plant. 141, 361-372. doi: 10.1111/j.1399-3054.2011. 01443.x

Breitkreuz, K. E., Allan, W. L., Van Cauwenberghe, O. R., Jakobs, C., Talibi, D., André, B., et al. (2003). A novel $\gamma$-hydroxybutyrate dehydrogenase: identification and expression of an Arabidopsis cDNA and potential role

\section{FUNDING}

This research was supported by funding from the Natural Sciences and Engineering Research Council (NSERC) of Canada as a Strategic Project Grant (BS and GB) and Individual Discovery Grants (BS), and from the Ontario Ministry of Agriculture Food and Rural Affairs (GB and BS).

\section{ACKNOWLEDGMENT}

The authors thank Dr. G. J. Hoover for recalculating the kinetic parameters from his manuscript so that they could be incorporated into Table $\mathbf{1 .}$

\section{SUPPLEMENTARY MATERIAL}

The Supplementary Material for this article can be found online at: http://journal.frontiersin.org/article/10.3389/fpls.2017.01399/ full\#supplementary-material

under oxygen deficiency. J. Biol. Chem. 278, 41552-41556. doi: 10.1074/jbc M305717200

Brikis, C. J., Zarei, A., Trobacher, C. P., DeEll, J. R., Akama, K., Mullen, R. T., et al. (2017). Ancient plant glyoxylate/succinic semialdehyde reductases: GLYR1s are cytosolic, whereas GLYR2s are localized to both mitochondria and plastids. Front. Plant Sci. 8:601. doi: 10.3389/fpls.2017.00601

Campbell, W. J., and Ogren, W. L. (1990). Gloxylate inhibition of ribulosebisphosphate carboxylase/oxygenase activation in intact, lysed, and reconstituted chloroplasts. Photosynth. Res. 23, 257-268. doi: 10.1007/ BF00034856

Ching, S. L. K., Gidda, S. K., Rochon, A., Van Cauwenberghe, O. R., Shelp, B. J., and Mullen, R. T. (2012). Glyoxylate reductase isoform 1 is localized in the cytosol and not peroxisomes in plant cells. J. Integr. Plant Biol. 54, 152-168. doi: 10.1111/j.1744-7909.2012.01103.x

Clark, S. M., Di Leo, R., Dhanoa, P. K., Van Cauwenberghe, O. R., Mullen, R. T., and Shelp, B. J. (2009). Biochemical characterization, mitochondrial localization, expression, and potential functions for an Arabidopsis $\gamma$-aminobutyrate transaminase that utilizes both pyruvate and glyoxylate. J. Exp. Bot. 60, 1743-1757. doi: 10.1093/jxb/erp044

Clough, S. J., and Bent, A. F. (1998). Floral dip: A simplified method for Agrobacterium-mediated transformation of Arabidopsis thaliana. Plant J. 16, 735-743. doi: 10.1046/j.1365-313x.1998.00343.x

Czechowski, T., Stitt, M., Altmann, T., and Udvardi, M. K. (2005). Genome-wide identification and testing of superior reference genes for transcript normalization. Plant Physiol. 139, 5-17. doi: 10.1104/pp.105. 063743

Emanuelsson, O., Nielsen, H., Brunak, S., and von Heijne, G. (2000). Predicting subcellular localization of proteins based on their N-terminal amino acid sequence. J. Mol. Biol. 300, 1005-1016. doi: 10.1006/jmbi.2000.3903

Eprintsev, A. T., Feedorin, D. N., Salnikov, A. V., and Igamberdiev, A. U. (2015). Expression and properties of the glyoxysomal and cytosolic forms of isocitrate lyase in Amaranthus caudatus L. J. Plant Physiol. 181, 1-8. doi: 10.1016/j.jplph. 2015.02.014

Fait, A., Yellin, A., and Fromm, H. (2005). GABA shunt deficiencies and accumulation of reactive oxygen intermediates: insight from Arabidopsis mutants. FEBS Lett. 579, 415-420. doi: 10.1016/j.febslet.2004.12.004

Foyer, C. H., Bloom, A. J., Queval, G., and Noctor, G. (2009). Photorespiratory metabolism genes, mutants, energetics, and redox signaling. Annu. Rev. Plant Biol. 60, 455-484. doi: 10.1146/annurev.arplant.043008.091948 
Gasic, K., Hernandez, A., and Korban, S. S. (2004). RNA extraction from different apple tissues rich in polyphenols and polysaccharides for cDNA library construction. Plant Mol. Biol. Rep. 22, 437-438. doi: 10.1007/BF02772687

Givan, C. V., and Kleczkowski, L. A. (1992). The enzymic reduction of glyoxylate and hydroxypyruvate in leaves of higher plants. Plant Physiol. 100, 552-556. doi: 10.1104/pp.100.2.552

Givan, C. V., Tsutakawa, S., Hodgson, J. M., David, N., and Randall, D. D. (1988). Glyoxylate reductase activity in pea leaf protoplasts. Nucleotide specificity and subcellular location. J. Plant Physiol. 132, 593-599. doi: 10.1016/S01761617(88)80260-8

Heineke, D., Riens, B., Grosse, H., Hoferichter, P., Peter, U., Flügge, U.-I., et al. (1991). Redox transfer across the inner chloroplast envelope membrane. Plant Physiol 95, 1131-1137. doi: 10.1104/pp.95.4.1131

Hood, E. E., Gelvin, S. B., Melchers, L. S., and Hoekema, A. (1993). New Agrobacterium helper plasmids for gene transfer to plants. Transgenic Res. 2, 208-218. doi: 10.1007/BF01977351

Hoover, G. J., Jørgensen, R., Rochon, A., Bajwa, V. S., Merrill, A. R., and Shelp, B. J. (2013). Identification of catalytically important amino acid residues for enzymatic reduction of glyoxylate in plants. Biochim. Biophys. Acta 1834, 2663-2671. doi: 10.1016/j.bbapap.2013.09.013

Hoover, G. J., Prentice, G. A., Merrill, A. R., and Shelp, B. J. (2007a). Glyoxylate reductase: studies of initial velocity, dead-end inhibition and product inhibition. Can. J. Bot. 85, 896-902. doi: 10.1139/B07-082

Hoover, G. J., Van Cauwenberghe, O. R., Breitkreuz, K. E., Clark, S. M., Merrill, A. R., and Shelp, B. J. (2007b). Glyoxylate reductase: general biochemical properties and substrate specificity for the recombinant protein, and developmental expression and implications for glyoxylate and succinic semialdehyde metabolism in planta. Can. J. Bot. 85, 883-895. doi: 10.1139/ B07-081

Igamberdiev, A. U., and Eprintsev, A. T. (2016). Organic acids: the pools of fixed carbon involved in redox regulation and energy balance in higher plants. Front. Plant Sci. 7:1042. doi: 10.3389/fpls.2016.01042

Igamberdiev, A. U., and Gardeström, P. (2003). Regulation of NAD and NADPdependent isocitrate dehydrogenases by reduction of levels of pyridine nucleotides in mitochondria and cytosol of pea leaves. Biochim. Biophys. Acta 1606, 117-125. doi: 10.1016/S0005-2728(03)00106-3

Kaplan, F., Kopka, J., Sung, D. Y., Zhao, W., Popp, M., Porat, M., et al. (2007). Transcript and metabolite profiling during cold acclimation of Arabidopsis reveals an intricate relationship of cold-regulated gene expression with modifications in metabolite content. Plant J. 50, 967-981. doi: 10.1111/j.1365313X.2007.03100.x

Karimi, M., Inze, D., and Depicker, A. (2002). GATEWAY vectors for Agrobacterium-mediated plant transformation. Trends Plant Sci. 7, 193-195. doi: 10.1016/S1360-1385(02)02251-3

Kinnersley, A. M., and Turano, F. J. (2000). $\gamma$-Aminobutyric acid (GABA) and plant responses to stress. CRC Crit. Rev. Plant Sci. 19, 479-509. doi: 10.1016/ S0735-2689(01)80006-X

Kleczkowski, L. A. (1995). Kinetics and regulation of the NAD(P)H-dependent glyoxylate-specific reductase from spinach leaves. Z. Naturforsch. 50, 21-28.

Kleczkowski, L. A., Randall, D. D., and Blevins, D. G. (1986). Purification and characterization of a novel NADPH(NADH)-dependent glyoxylate reductase from spinach leaves. Biochem. J 239, 653-659. doi: 10.1042/bj2390653

Kleczkowski, L. A., Randall, D. D., and Edwards, G. E. (1991). Oxalate as a potent and selective inhibitor of spinach (Spinacia oleracea) leaf NADPH-dependent hydroxypyruvate reductase. Biochem. J. 276, 125-127. doi: 10.1042/bj2760125

Kotchoni, S. O., Kuhns, C., Ditzer, A., Kirch, H. H., and Bartels, D. (2006). Overexpression of different aldehyde dehydrogenase genes in Arabidopsis thaliana confers tolerance to abiotic stress and protects plants against lipid peroxidation and oxidative stress. Plant Cell Environ. 29, 1033-1048. doi: 10. 1111/j.1365-3040.2005.01458.x

Kunze, M., Pracaroenwattana, I., Smith, S. M., and Hartig, A. (2006). A central role for the peroxisomal membrane in glyoxylate cycle function. Biochim. Biophys. Acta 1763, 1441-1452. doi: 10.1016/j.bbamcr.2006.09.009

Livak, K. J., and Schmittgen, T. D. (2001). Analysis of relative gene expression data using real-time quantitative PCR and the $2^{-\Delta \mathrm{Ct}}$ method. Methods 25, 402-408. doi: 10.1006/meth.2001.1262

Lu, Y., Li, Y., Yang, Q., Zhang, Z., Chen, Y., Zhang, S., et al. (2014). Suppression of glycolate oxidase causes glyoxylate accumulation that inhibits photosynthesis through deactivating Rubisco in rice. Physiol. Plant. 150, 463-476. doi: 10.1111/ ppl.12104

Ludewig, F., Hüser, A., Fromm, H., Beauclair, L., and Bouché, N. (2008). Mutants of GABA transaminase (POP2) suppress the severe phenotype of succinic semialdehyde dehydrogenase (ssadh) mutants in Arabidopsis. PLoS ONE 3:e3383. doi: 10.1371/journal.pone.0003383

Mano, J. (2012). Reactive carbony species: their production from lipid peroxides, action in environmental stress, and the detoxification mechanism. Plant Physiol. Biochem. 59, 90-97. doi: 10.1016/j.plaphy.2012.03.010

McLean, M. D., Yevtushenko, D. P., Deschene, A., Van Cauwenberghe, O. R., Makhmoudova, A., Potter, J. W., et al. (2003). Overexpression of glutamate decarboxylase in transgenic tobacco plants confers resistance to the northern root-knot nematode. Mol. Breed. 11, 277-285. doi: 10.1023/A:1023483 106582

Mekonnen, D. W., and Ludewig, F. (2016). Phenotypic and chemotypic studies using Arabidopsis and yeast reveal that GHB coverts to SSA and induces toxicity. Plant. Mol. Biol. 91, 429-440. doi: 10.1007/s11103-016-0475-6

Modde, K., Timm, S., Florian, A., Michl, K., Fernie, A. R., and Bauwe, H. (2017). High serine:glyoxylate aminotransferase activity lowers leaf daytime serine levels, inducing the phosphoserine pathway in Arabidopsis. J. Exp. Bot. 68, 643-656. doi: 10.1093/jxb/erw467

Montiel, G., Zarei, A., Körbes, A. P., and Memelink, J. (2011). The jasmonateresponsive element from the ORCA3 promoter from Catharanthus roseus is active in Arabidopsis and is controlled by the transcription factor AtMYC2. Plant Cell Physiol. 52, 578-587. doi: 10.1093/pcp/pcr016

Murashige, T., and Skoog, F. (1962). A revised medium for rapid growth and bioassays with tobacco tissue cultures. Physiol. Plant. 15, 473-497. doi: 10.1111/ j.1399-3054.1962.tb08052.x

Narsai, R., Howell, K. A., Carroll, A., Ivanova, A., Millar, A. H., and Whelan, J. (2009). Defining core metabolic and transcriptomic responses to oxygen availability in rice embryos and young seedlings. Plant Physiol. 151, 306-322. doi: $10.1104 /$ pp.109.142026

Ni, M., Cul, D., Einstein, J., Narasimhulu, S., Vergara, C. E., and Gelvin, S. B. (1995). Strength and tissue specificity of chimeric promoters derived from the octopine and manopine synthase genes. Plant J. 7, 661-676. doi: 10.1046/j.1365-313X. 1995.7040661.x

Nikiforova, V. J., Giesbertz, P., Wiemer, J., Bethan, B., Looser, R., Liebenberg, V., et al. (2014). Gloxylate, a new marker metabolite of Type 2 diabetes. J. Diabetes Res. 2014:685204. doi: 10.1155/2014/685204

Oberschall, A., Deak, M., Torok, K., Sass, L., Vass, I., Kovacs, I., et al. (2000). A novel aldose/aldehyde reductase protects transgenic plants against lipid peroxidation under chemical and drought stresses. Plant J. 24, 437-446. doi: 10.1111/j.1365313X.2000.00885.x

Palanivelu, R., Brass, L., Edlund, A. F., and Preuss, D. (2003). Pollen tube growth and guidance is regulated by POP2, an Arabidopsis gene that controls GABA levels. Cell 114, 47-59. doi: 10.1016/S0092-8674(03) 00479-3

Peterhansel, C., Horst, I., Niessen, M., Blume, C., Kebish, R., Kürkcüoglu, S., et al. (2010). Photorespiration. The Arabidopsis Book. Rockville, MD: The American Society of Plant Biologists.

Puchegger, S., Redl, B., and Stöffler, G. (1990). Purification and properties of a thermostable fumarate hydratase from the archaeobacterium Sulfolobus solfataricus. J. Gen. Microbiol. 136, 1537-1541. doi: 10.1099/00221287-136-81537

Ros, R., Muñoz-Bertomeu, J., and Krueger, S. (2014). Serine in plants: biosynthesis, metabolism, and functions. Trends Plant Sci. 19, 564-569. doi: 10.1016/j.tplants. 2014.06.003

Shelp, B. J., Bown, A. W., and McLean, M. D. (1999). Metabolism and functions of gamma-aminobutyric acid. Trends Plant Sci. 4, 446-452. doi: 10.1016/S13601385(99)01486-7

Shelp, B. J., Bozzo, G. G., Trobacher, C. P., Brikis, C. J., Chiu, G., and Bajwa, V. S. (2012a). Strategies and tools for studying GABA metabolism and function: I. Pathway structure. Botany 90, 651-668. doi: 10.1139/B2 012-030

Shelp, B. J., Bozzo, G. G., Zarei, A., Simpson, J. P., Trobacher, C. P., and Allan, W. L. (2012b). Strategies and tools for studying the metabolism and function of $\gamma$-aminobutyrate in plants. II. Integrated analysis. Botany 90, 781-793. doi: 10.1139/B2012-041 
Shelp, B. J., and Zarei, A. (2017). Subcellular compartmentation of 4aminobutyrate (GABA) metabolism in Arabidopsis: an update. Plant Signal. Behav. 12:e13222244. doi: 10.1080/15592324.2017.1322244

Shi, Y., Mowery, R. A., Ashley, J., Hentz, M., Ramirez, A. J., Bilgicer, B., et al. (2012). Abnormal SDS-PAGE migration of cytosolic proteins can identify domains and mechanisms that control surfactant binding. Protein Sci. 21, 1197-1209. doi: $10.1002 /$ pro. 2107

Simpson, J. P., Di Leo, R., Dhanoa, P. K., Allan, W. L., Makhmoudova, A., Clark, S. M., et al. (2008). Identification and characterization of a plastid-localized Arabidopsis glyoxylate reductase isoform: comparison with a cytosolic isoform and implications for cellular redox homeostasis and aldehyde detoxification. J. Exp. Bot. 59, 2545-2554. doi: 10.1093/jxb/ern123

Srivastava, S., Brychkova, G., Yarmolinsky, D., Soltabayeva, A., Samani, T., and Sagi, M. (2017). Aldehyde oxidase 4 plays a critical role in delaying silique senescence by catalyzing aldehyde detoxification. Plant Physiol. 173, 1977-1997. doi: $10.1104 /$ pp.16.01939

Sunkar, R., Bartels, D., and Kirch, H. H. (2003). Overexpression of a stressinducible aldehyde dehydrogenase gene from Arabidopsis thaliana in transgenic plants improves stress tolerance. Plant J. 35, 452-464. doi: 10.1046/j.1365-313X. 2003.01819.x

Taylor, N. L., Ströhner, E., and Millar, H. A. (2014). “Arabidopsis organelle isolation and characterization," in Arabidopsis Protocols, Methods in Molecular Biology, Vol. 1062, eds J. L. Sanchez-Serrano and J. Salinas (New York: Springer Business Media), 551-572. doi: 10.1007/978-1-62703-580-4-29

Timm, S., Florian, A., Jahnke, K., Nunes-Nesi, A., Fernie, A. R., and Bauwe, A. (2011). The hydroxypyruvate-reducing system in Arabidopsis: multiple enzymes for the same end. Plant Physiol. 155, 694-705. doi: 10.1104/pp.110. 166538

Toyokura, K., Watanabe, K., Oiwaka, A., Kusano, M., Tameshige, T., Tatematsu, K., et al. (2011). Succinic semialdehyde dehydrogenase is involved in the robust patterning of Arabidopsis leaves along the adaxial-abaxial axis. Plant Cell Physiol. 52, 1340-1353. doi: 10.1093/pcp/pcr079

Tuin, L. G., and Shelp, B. J. (1994). In situ $\left[{ }^{14} \mathrm{C}\right]$ glutamate metabolism by developing soybean cotyledons I. Metabolic routes. J. Plant Physiol. 143, 1-7. doi: 10.1016/S0176-1617(11)82089-4

Weber, H., Chetelat, A., Reymond, P., and Farmer, E. E. (2004). Selective and powerful stress gene expression in Arabidopsis in response to malondialdehyde. Plant J. 37, 877-888. doi: 10.1111/j.1365-313X.2003.02013.x

Werner, A. K., and Witte, C.-P. (2011). The biochemistry of nitrogen mobilization: purine ring catabolism. Trends Plant Sci. 16, 381-387. doi: 10.1016/j.tplants. 2011.03.012
Wigge, B., Krömer, S., and Gardeström, P. (1993). The redox levels and the subcellular distribution of pyridine nucleotides in illuminated barley leaf protoplasts studied by rapid fractionation. Physiol. Plant. 88, 10-18. doi: 10. 1111/j.1399-3054.1993.tb01754.x

Yamauchi, Y., Hasegawa, A., Taninaka, A., Mizutani, M., and Sugimoto, Y. (2011). NADPH-dependent reductases invoved in the detoxification of reactive carbonyls in plants. J. Biol. Chem. 286, 6999-7009. doi: 10.1074/jbc.M110. 202226

Yokota, A., Haga, S., and Kitaoka, S. (1985). Purification and some properties of glyoxylate reductase $\left(\mathrm{NADP}^{+}\right)$and its functional location in mitochondria in Euglena gracilis Z. Biochem. J. 227, 211-216. doi: 10.1042/bj2270211

Yokota, A., and Kitaoka, S. (1979). Occurrence and operation of the glycollateglyoxylate shuttle in mitochondria of Euglena gracilis Z. Biochem. J. 184, 189-192. doi: 10.1042/bj1840189

Yu, L., Jiang, J., Zhang, C., Jiang, L., Ye, N., Lu, Y., et al. (2010). Glyoxylate rather than ascorbate is an efficient precursor for oxalate biosynthesis in rice. J. Exp. Bot. 61, 1625-1634. doi: 10.1093/jxb/erq028

Zarei, A., Chiu, G. Z., Yu, G., Trobacher, C. P., and Shelp, B. J. (2017). Salinityregulated regulation of genes involved in GABA metabolism and signaling. Botany 95, 621-627. doi: 10.1139/cjb-2016-0304

Zarei, A., Körbes, A. P., Younessi, P., Montiel, G., Champion, A., and Memelink, J. (2011). Two GCC boxes and AP2/ERF-domain transcription factor ORA59 in jasmonate/ethylene-mediated activation of the PDF1.2 promoter in Arabidopsis. Plant Mol. Biol. 75, 321-331. doi: 10.1007/s11103010-9728-y

Zarei, A., Trobacher, C. P., and Shelp, B. J. (2016). Arabidopsis aldehyde dehydrogenase 10 family members confer salt tolerance through putrescinederived 4-aminobutyrate (GABA) production. Sci. Rep. 6:35115. doi: 10.1038/ srep35115

Conflict of Interest Statement: The authors declare that the research was conducted in the absence of any commercial or financial relationships that could be construed as a potential conflict of interest.

Copyright (C) 2017 Zarei, Brikis, Bajwa, Chiu, Simpson, DeEll, Bozzo and Shelp. This is an open-access article distributed under the terms of the Creative Commons Attribution License (CC BY). The use, distribution or reproduction in other forums is permitted, provided the original author(s) or licensor are credited and that the original publication in this journal is cited, in accordance with accepted academic practice. No use, distribution or reproduction is permitted which does not comply with these terms. 